\title{
Cheio de tudo: Paulo Leminski y el budismo zen* Cheio de tudo: Paulo Leminski and Zen Buddhism
}

\author{
Felipe Cussen \\ Instituto de Estudios Avanzados/ Universidad de Santiago de Chile \\ felipecussen@gmail.com
}

En este artículo intento demostrar que la influencia del budismo zen y el modelo del haiku en la obra de Paulo Leminski no se limita simplemente a una serie de tópicos temáticos, sino que resulta determinante en el desarrollo formal de su poesía breve. Esta influencia es paralela a la de otros lenguajes, como la fotografía y la publicidad, y además se conjuga con las propuestas de los poetas concretos, quienes también se interesaron en la poesía japonesa. Finalmente analizo las diversas versiones y traducciones de uno de sus últimos poemas, en el que se observan las posibilidades expresivas del vacío.

Palabras clave: Paulo Leminski, poesía brasileña, budismo zen, haiku, vacío.

In this article I pretend to show that the influence of Zen Buddhism and haiku model in the work of Paulo Leminski is not just limited to a series of thematic topics, but it is essential to the formal development of his short poetry. This influence is parallel to other languages, as photography and publicity, and is also combined with the proposals of the concrete poets, which were interested too in japanese poetry. Finally I analyze diverse versions and translations of one of his last poems, in which the expressive possibilities of emptiness are observed.

Keywords: Paulo Leminski, brazilian poetry, zen buddhism, haiku, emptiness.

Recibido: 1 de noviembre de 2010

Aprobado: 25 de marzo de 2011

\footnotetext{
* Este artículo forma parte de mi proyecto "La mística en los límites de la poesía contemporánea" (Proyecto Fondecyt de Iniciación a la Investigación \#11080248), y está basado en la ponencia homónima leída el 23 de septiembre de 2009 en las "Cuartas jornadas brasileñas y Primeras Jornadas sobre las culturas de lengua portuguesa en el mundo", en la Universidad de Chile. Agradezco especialmente las sugerencias de Régis Bonvicino e Iván García López, así como la colaboración en la recolección bibliográfica de Mario Cámara, Virginia Gutiérrez, Pablo Vergara y Jimena Castro.
} 
"No tenía nada de budista"

(Régis Bonvicino)

1.

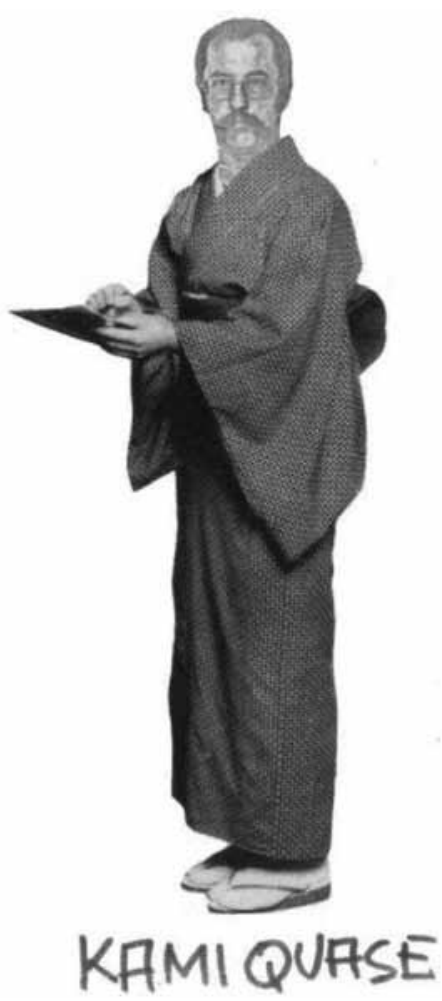

"Kamiquase" (Caprichos \& relaxos 132), casi un kamikaze, es una de las tantas máscaras que Paulo Leminski (Curitiba, 1944-1989) inventó para presentarse. Ese montaje de imágenes y palabras se replicó en las sucesivas yuxtaposiciones con que barajaba su identidad, tal como las recoge Fabrício Marques: "Um bandido que sabe latim. Parnasiano-chic. Caboclomonge-black-beat-zen. Útil operário do signo. Guerreiro da palavra. Centauro homemcavalo-metade decadente alexandrino bizantino e metade bandeirante pioneiro Marcopolo" (16). Sus compañeros también debieron recurrir a términos similares para intentar definirlo; así describe Haroldo de Campos la fulgurante aparición de un joven Leminski en la "Semana Nacional de Poesia de Vanguarda" de 1963: "Rimbaud curitibano com físico de judoca, escandindo versos homéricos, como se fosse um discípulo zen de Bashô" (Leminski, Caprichos \& relaxos 8), y lo reitera algunas décadas después en un poema elegíaco: "samurai mestiço/ . . . polaco polingue/ . . . jovem rimbaud fileleno" (Crisantempo 110). Esta dispersión no solo corresponde a esa condición de mestizo polaco y negro, sino aún más a su infinita multiplicidad de referentes culturales, según detalla Ademir Assunção:

da poesia clássica chinesa ao blues afro-americano, da patafísica de Jarry ao vigor samurai de Yukio Mishima, 
dos clássicos gregos ao rock-'n'-roll, do haicai japonês ao Tropicalismo, de Cruz e Sousa a Leon Trótski, de James Joyce a John Fante, de Samuel Beckett a Cartola, de poemas do Egito Antigo ao videotexto, do supraerudito ao supremo popular, do universo cósmico de uma biblioteca aos movimentos mundanos. (Dick y Calixto 31)

No sorprenderá, entonces, que su producción abarque desde la prosa experimental de su inaugural Catatau, pasando por cuentos, poemas, traducciones, biografías, ensayos, cartas, ampliándose a soportes como la poesía visual, el graffiti, la publicidad, la televisión y, quizás lo que más le enorgullecía, las letras de canciones. Ese fue el modo de cumplir con su lema: "o poeta para ser poeta tem que ser mais que poeta" (Leminski y Bonvicino 49).

Formado en la matriz de la poesía concreta, Leminski hace suyo el proyecto antropofágico de Oswald de Andrade y asume las ventajas de la posición periférica. En vez de cerrar las fronteras, "[e]u optei, estrategicamente, por ser colonizado" (Vaz 188). Luego de aprender distintas lenguas y conocer sus tradiciones literarias, forma su propio camino a partir de la "deslectura", de los "desvíos en relación a los moldes ya fijados" (María Esther Maciel en Leminski, Leminskiana 296). Esta soltura se une a un cierto relajo que lo distingue de sus ceñudos maestros del grupo Noigandres: "Leminski produziu uma 'descompressão' no rigor da linguagem herdada da poesia concreta" (Carlos Ávila en Leminski y Bonvicino 243). Tal como proponía en el prefacio a una antología generacional en 1978, había llegado el momento de dejar de lado "planos-projetos-manifestos-plataformas de alta definição" y abrir un espacio para una "indeterminação maior, maior margem ao acaso", uniendo definitivamente la poesía y la vida (Leminski y Bonvicino 191).

2.

Desde aquí podemos comenzar a trazar los vínculos hacia algunos conceptos del budismo zen, pero no sin antes que prevenir que cualquier tentativa de estudiar algún aspecto aislado de la obra de Leminski resultaría absurda si se olvida la extrema mixtura y diversidad de referentes implicados. La tarea es aún más difícil cuando se trata precisamente de una influencia tan inasible como el budismo zen, que, como enfatizan sus practicantes, no es ni una religión, ni un sistema filosófico, sino más bien una disciplina práctica que propone un camino de anulación hacia el satori, generalmente traducido como "iluminación", pero que considero más sencillo de comparar con un término computacional: un "reseteo". El zen, pues, resiste cualquier intento de explicación racional, pues solo puede comprenderse desde la experiencia directa. Por ello, también implica una crítica directa al lenguaje: "las palabras son palabras y nada más. Si las palabras cesan de estar acordes con los hechos, ha llegado el momento de romper con las palabras y volver de nuevo a los hechos", explica D. T. Suzuki (79-80), uno de sus principales divulgadores en Occidente. Por este motivo, su uso está basado en "afirmacions simples que, per la seva simplicitat, semblen críptiques o que constaten obvietats", o bien en contradicciones y paradojas, mediante las cuales "les paraules obren un espai a la vacuïtat" (Bouso 99). 
El acercamiento de Leminski a las filosofías orientales fue muy temprano, y según su biógrafo Toninho Vaz debería haberse producido durante su estancia en un monasterio benedictino a partir de los doce años, donde también estudió griego y latín. En una carta de 1963, el mismo año de su contacto con los poetas concretos, afirma estar traduciendo haikus japoneses (Vaz 78), y en 1966 comienza su práctica del judo. También lee al ya mencionado Suzuki y a Alan Watts, quienes habían influenciado notoriamente a poetas del movimiento beat como Allen Ginsberg, Jack Kerouac y Gary Snyder. En los años siguientes, esta inmersión intelectual y activa se irá profundizando y mezclando con intereses paralelos como el movimiento tropicalista. En todo caso, como propone Antonio Risério (Dick y Calixto 366), más que determinar la procedencia de esta influencia, lo que importa es el modo en que Leminski las configuró. Para ello, vale la pena detenerse tanto en la articulación vital del arte dentro del zen, y sus relaciones con algunos aspectos de la estética contemporánea.

Dentro de esta concepción de mundo, se manifiesta una estrecha relación entre vida, arte y espiritualidad. Prácticas como la ceremonia del té, el ikebana, las artes marciales, el teatro, la caligrafía, la pintura o la poesía buscan favorecer el camino de aprendizaje, mediante una fusión del artista con la naturaleza, que debe hacerse a un lado para que el objeto de referencia pueda expresarse. Si bien en Leminski generalmente primará la figura de un sujeto (aunque sea enmascarado o en crisis), lo que le resulta atractivo es la completa integración de la práctica artística y física en la vida cotidiana. Solo mediante la reiteración y la constancia es posible llegar a un arte sin esfuerzo, sin pretensiones, o, por ponerlo en palabras más chilenas, "como que no quiere la cosa"... Solo se busca ejercer la gratuidad y el azar, sin responder a ninguna demanda, sin pretender decir nada. Para Leminski, la poesía será un "inutensílio" (Ensaios e Anseios Crípticos 78).

En Vida, su proyecto de cuatro biografías sobre grandes personajes (que, como sugiere Frederico Barbosa, podría ser entendida como un autorretrato (Dick y Calixto 287)), Leminski escoge a Cruz e Sousa, Jesucristo, Trotski, y al poeta japonés Matsuo Basho. Además de su vida errante y dedicada exclusivamente al cultivo de la poesía, este le resulta atractivo porque fue el principal impulsor del haiku ${ }^{1}$, la forma más breve de la tradición japonesa. En palabras del propio Basho, "Un haiku es lo que ocurre aquí y ahora" (20). Se trata, también, de la forma poética por excelencia del budismo zen y por eso se ofrece, según plantea Roland Barthes en El imperio de los signos, como una detención del lenguaje, destinada "a vaciar, a pasmar, a secar la cháchara incontenible del alma" (91).

Durante el siglo XX, esta forma basada en la simplicidad y la espontaneidad traspasó las fronteras de Japón, llegando a ser practicada y leída en los más diversos lugares. Masuda Goga y Paulo Franchetti han estudiado la historia del haiku en Brasil, destacando que su primera implantación no se debe a la voluminosa inmigración japonesa de comienzos de siglo, sino que

1 Para mayor información sobre este género, remito, además de algunos autores que citaré a continuación, a El libro del haiku de Alberto Silva, y a los textos seleccionados por Reynaldo Jiménez en Haiku. 
fue presentado por Afrânio Peixoto a partir de traducciones francesas. Luego fue desarrollado tanto por los descendientes nipones como por escritores brasileros, adoptando gran popularidad, y se reconoce a Leminski como uno de sus principales difusores. Ahora bien, más que pensar en la posible importancia de la presencia japonesa en Brasil y en especial en una ciudad multicultural como Curitiba, creo que en su particular predilección por el haiku confluyen su voracidad por el aprendizaje de cualquier lengua extranjera (que en este caso específico se apoyaba en estudios hoy considerados clásicos, como los de Donald Keene y Robert Blyth), a las ya mencionadas influencias del contexto beat y contracultural de fines de los ' 60 (prolongadas luego en la poesía marginal del Brasil de los '70) y, por supuesto, al interés que los poetas concretos (vía Pound y Fenollosa) habían demostrado por la poesía china y japonesa. Pero además habría que considerar que la síntesis extrema del haiku no solo se corresponde con la estética minimalista de la poesía concreta, sino que también coincide con otros modelos atractivos para Leminski: el eslogan publicitario y la fotografía. Respecto del primero, podemos citar a Fabrício Marques, quien especifica los vínculos de su escritura con la publicidad, la principal actividad laboral de Leminski: "Podem-se identificar aí elementos como concisão, coloquialismo, trocadilhos e um certo apetite para slogans, características que, ao lado de neologismos e recursos visuais, são ingredientes da poesia de Leminski que impregnam o universo da publicidade" (Dick y Calixto 188). En cuanto a la fotografía, junto con recordar que en 1976 publicó un libro junto a Jack Pires (Quarenta clics em Curitiba), en el que reunían "fotos e poemas como ideogramas japoneses" (Anseios crípticos 215), también se debe destacar esta particular formulación en su ensayo "Click: Zen e arte de fotografia": "Foto, hai-kai: elipse do eu, eclipse da retórica" (Anseios crípticos 115). Barthes, por cierto, también vinculó el haiku con la fotografía en cuanto su capacidad comunicativa: "El sentido en él solo es un flash . . .; pero el flash del haikú no aclara, no revela nada; es el de una fotografía que se tomara muy cuidadosamente (a la japonesa), pero habiendo olvidado colocar la película en la cámara" (104). La brevedad del formato y la inmediatez de la escritura se convierten, entonces, en una barrera para los excesos discursivos y las sobreexplicaciones que interrumpirían la fluidez del poema.

Muchos poetas occidentales han escrito sus haikus creyendo que basta con poner cara de concentración y nombrar un cerezo, un plato de arroz, una pagoda o cualquier tópico de la cultura japonesa. Para Leminski, en cambio, esta tradición antigua y ajena significaba algo más. Se acerca a ella del mismo modo que en sus otras búsquedas, intentando encontrar un nuevo aliciente para la experimentación poética. En su ensayo "Bonsai. Niponização e miniaturização da poesia brasileira", por ejemplo, indica las coincidencias del arte occidental moderno con el arte japonés tradicional, comparando las portmanteau-words de Joyce Joyce con las "kaketokoba" o "palabras colgadas", la música minimal de Philip Glass con la música japonesa tradicional y, por supuesto, la tendencia a la miniaturización y síntesis poética (Anseios crípticos 2124 ). Precisamente hacia el final de su biografía de Basho (Vida 129-30) incluye una serie de poemas breves occidentales que podrían considerarse descendientes de Basho, como "In a station of the metro" de Pound, y otros de Oswald de Andrade, Wallace Stevens, Tablada, Borges, Paz, finalizando en Pedro Xisto, el más orientalizado de los poetas 
concretos, a quien también conoció en 1963. Resulta muy atractivo, además, el modo en que se hace cargo de las dificultades de traducción del haiku japonés (una lengua "vaga, fluida, cheia de gerúndios" (90)), al proponer que para esa tarea es preciso hacerse cargo de los recursos propios de la vanguardias: "espacializações, cores, tipias, grafias, 'maneirismos', tais como a tradição literária do Ocidente os concebe" (Vida 89).

Esta fue, por cierto, la estrategia de apropiación que cumplieron los poetas concretos tanto en sus traducciones como en sus remezclas o "transcriações" de textos ajenos. Quisiera ocupar algunas páginas para ejemplificarlo, mostrando esta variedad de posibilidades a partir de la elección de un mismo referente, el poema más famoso de Matsuo Basho. Para hacernos una primera idea, podemos leer esta traducción de Antonio Cabezas:

Un viejo estanque.

Se zambulle una rana:

ruido del agua.

(Jaikus inmortales 33)

O esta (demasiado mexicana, a mi juicio) de Octavio Paz:

Un viejo estanque

salta una rana izas!

chapaleteo.

(Obra poética II 624)

En su biografía, Leminski lo traduce de manera similar a la de Cabezas:

$$
\begin{aligned}
& \text { velha lagoa } \\
& \text { o sapo salta } \\
& \text { o som da água } \\
& \text { (Vida 81) }
\end{aligned}
$$

Unas páginas más adelante incluye dos traducciones. La segunda, de Décio Pignatari, recurre a estrategias vanguardias como las portmanteau-words y la espacialización, para conseguir una versión más expresiva:

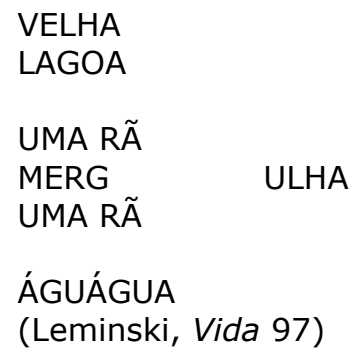

La primera, de Haroldo de Campos, había sido publicada dentro de su ensayo "Haicai: homenagem à síntese" (incluido en $A$ arte no horizonte do provável), de 1958: 


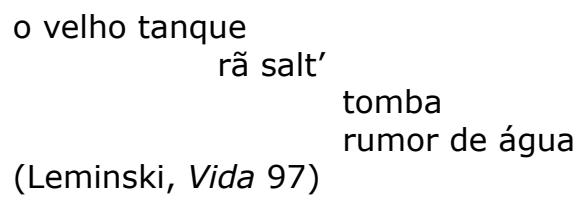

Haroldo señalaba que había buscado darle un desarrollo fílmico. Julio Plaza, frecuente colaborador de los poetas concretos, realiza a comienzos de los 80 una traducción intersemiótica a videotexto, lenguaje visual y montaje fotográfico:

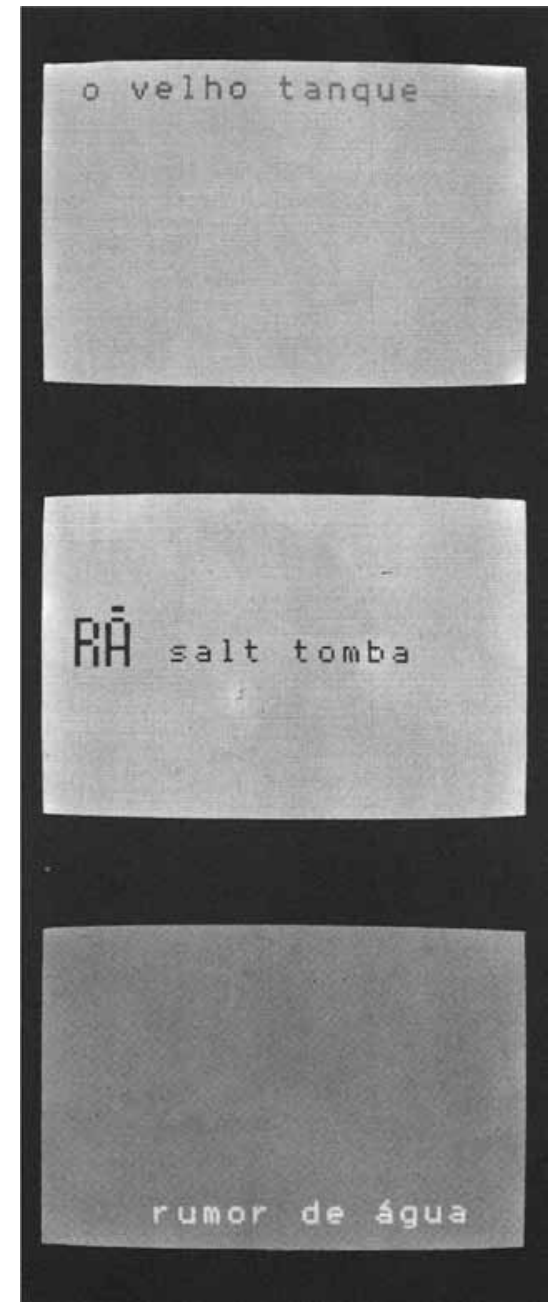



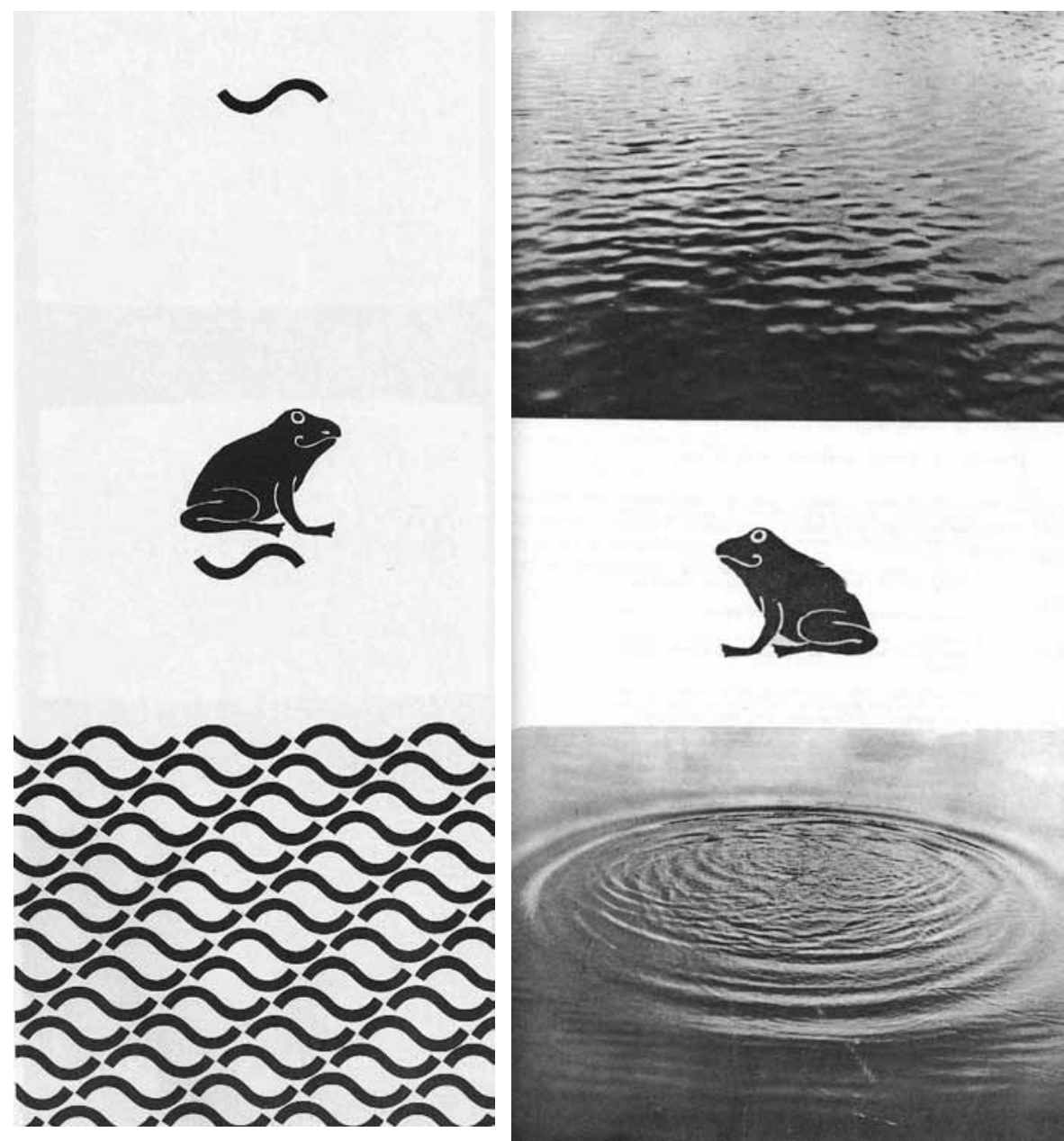

\section{(Tradução intersemiótica 117-19)}

Y finalmente podemos agregar la "intradução" que hace Augusto de Campos en "rã de bashô", donde la letra "a", con color verde, emula a la rana saltando sobre el fondo azul. Al igual que en los otros ejemplos de los poetas concretos, los recursos visuales permiten revivir la experiencia instantánea y sorpresiva captada por Bashô ya hace siglos².

2 Dentro del ámbito brasileño hay otras versiones que también enfatizan los aspectos gráficos, como las de Josely Vianna Baptista y Lena Jesus Ponte, incluidas en una extensa lista de traducciones de este poema ("Antologia da Rã"). Este interés, obviamente, ha sido compartido en otras latitudes: un ejemplo muy interesante es The Basho Variations de Steve McCaffery donde, luego de citar las minúsculas versiones de Dom Sylvester Houedard ("Frog/ pond/ plop") y bp Nichol ("Fog/ prondl/ pop"), emprende sus propias variaciones en un ejercicio parecido a los Ejercicios de estilo de Raymond Queneau. 


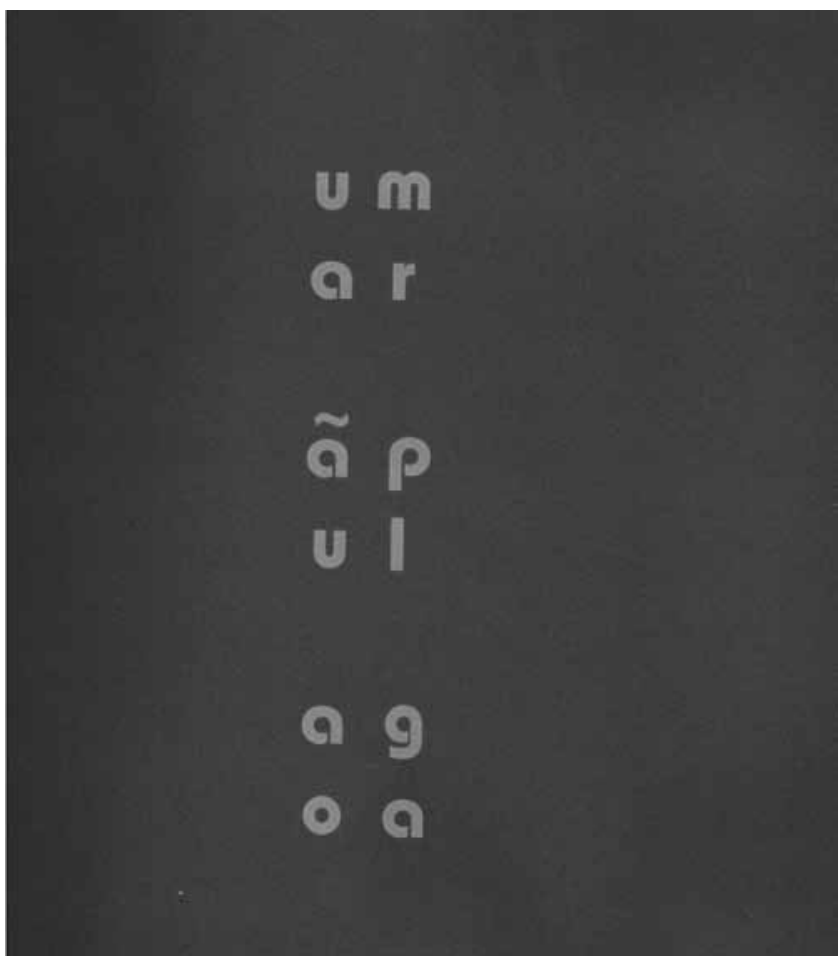

El propio Leminski, además de la traducción en su biografía de Basho, incluyó a esta rana dentro de otras obras. En Catatau aparece intempestiva y sonoramente: "O sapo pupapipa, águacai, shimbum!" (98), y en su libro La vie en close la yuxtapone con un referente muy distinto bajo el título, en lo que podría leerse como un arte poética, al fundir el rigor concretista de estirpe mallarmeana con la soltura del zen:

$$
\begin{aligned}
& \text { MALLARMÉ BASHÔ } \\
& \text { um salto de sapo } \\
& \text { jamais abolirá } \\
& \text { o velho poço } \\
& \text { (108) }
\end{aligned}
$$

En estricto rigor, esto no es un haiku: tiene título, no cumple exactamente con el esquema métrico tradicional (5-7-5 sílabas), y, más que una anulación del yo, parece un ejercicio intelectual. También en otros de sus supuestos haiku ocupa rimas, las que no están presentes en el modelo japonés. Como explica Franchetti, Leminski ha realizado una "assimilação brasileira do haicai, em que o haicai passa a ser apenas, como nome e como forma, uma indicação de origem" ("Haicai, haicais"). Del mismo modo que los poetas concretos, no pretenderá simplemente imitar los modelos japoneses, sino traerlos a un nuevo contexto y sumarlos a su mezcla. Tanto en aquellos textos más cercanos al haiku, como en sus numerosos poemas breves, lo 
que prevalecerá de esta adaptación es la tendencia a la síntesis, la abolición de la referencia mediante la rarefacción (según explica al inicio de Distraídos venceremos (7)), y el tono fresco y suelto, muchas veces cercano a un chiste rápido. Este tono responderá a la actitud de práctica constante y cotidiana que busca alcanzar una escritura sin cálculos pero tan certera y rápida como un flash o un golpe de judo: "Antigamente, eu trabalhava mais no sentido de adquirir aquela perícia artesanal que todo mundo tem que ter. Agora, acho que as coisas estão mais automatizadas em mim. Quer dizer, com dois toques eu estou chutando em gol" (Vaz 313).

\section{3.}

Para muchos, luego de su monumental Catatau, la predilección por este tipo de poesía significó una renuncia a la experimentación (Pignatari, en Vaz 394), que derivó en una mera fórmula (Dick, en Dick y Calixto 158) o agotamiento y banalización (Bonvicino, en Leminski y Bonvicino 218). Si bien es cierto que sus colecciones de los 80 resultan irregulares, considero que hay momentos de particular potencia dentro de su poesía breve. Hay un poema que quisiera analizar en detalle, pues además de ser uno de mis favoritos, creo que es en el que mejor se ejemplifica el modo en que Leminski asume el influjo del budismo zen.

La primera vez que lo leí fue en la antología Leminskiana. Esta es su versión original:

vazio agudo

ando meio

cheio de tudo

(120)

Y esta es la traducción al español de Mario Cámara:

vacío agudo

ando medio

lleno de todo

(121)

De acuerdo con esta versión, es posible entender estos versos como el proceso gradual de un sujeto que, una vez despierto por este vacío agudo, tiende hacia una plenitud de carácter positivo. Recuerdo que en esa ocasión me produjo un efecto similar al hermoso poema "Mattina" de Ungaretti: "M'illumino/ d'immenso" (121).

Esta primera lectura, sin embargo, se complejizó cuando conocí el contexto específico en el que este poema fue escrito. Se trata del libro póstumo Winterverno, compuesto por poemas de Leminski y dibujos de João Suplicy, los que fueron creados de manera compulsiva y azarosa durante sus encuentros en São Paulo, en servilletas y papeles que luego fueron recogidos por Josely Vianna Baptista. Ella los califica como "haiga (versos e desenhos que conversam)", y efectivamente pueden considerarse dentro de ese género, que a juicio de Alan Watts representa "the most 'extreme' form of sumi painting 
-the most spontaneous, artless, and rough, replete with all those 'controlled accidents' of the brush in which they exemplify the marvelous meaningless of nature itself" (176). Ese carácter apresurado e improvisado se observa claramente en algunos de los originales incluidos en Winterverno:
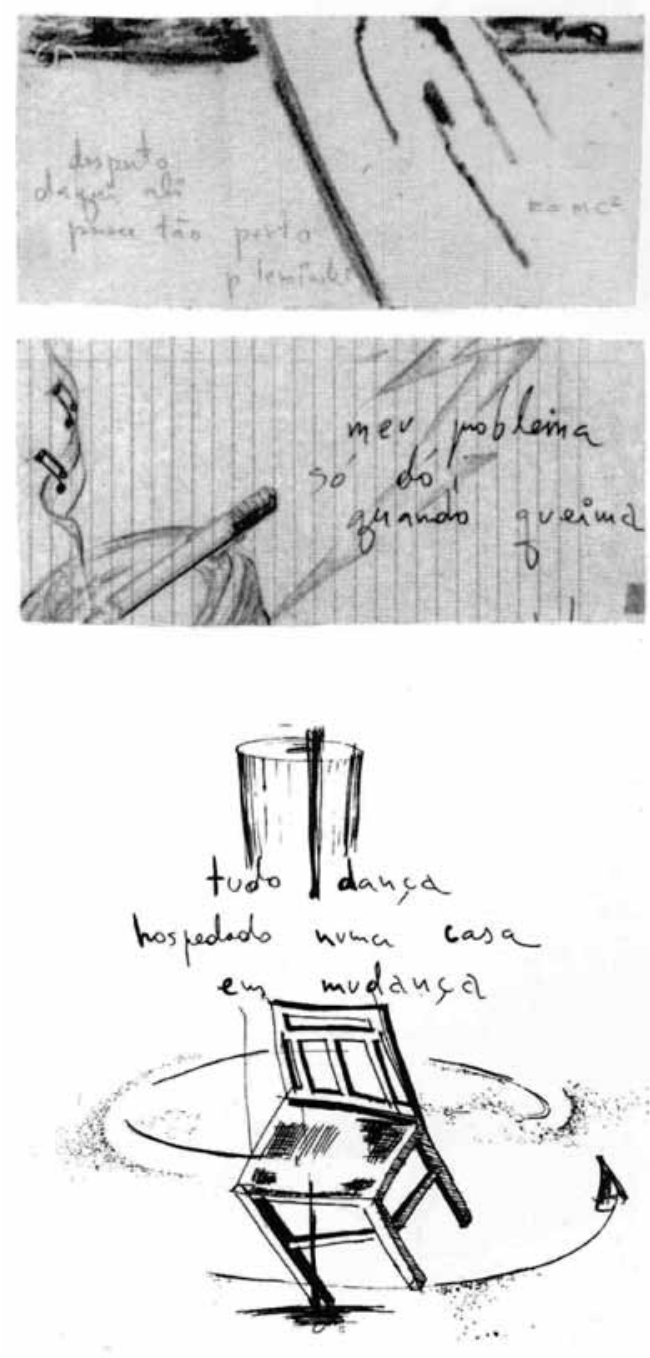

En la versión de este libro, el poema aparece inscrito dentro de la imagen de la luna cuyas puntas son muy agudas, pues está a punto de desaparecer: 


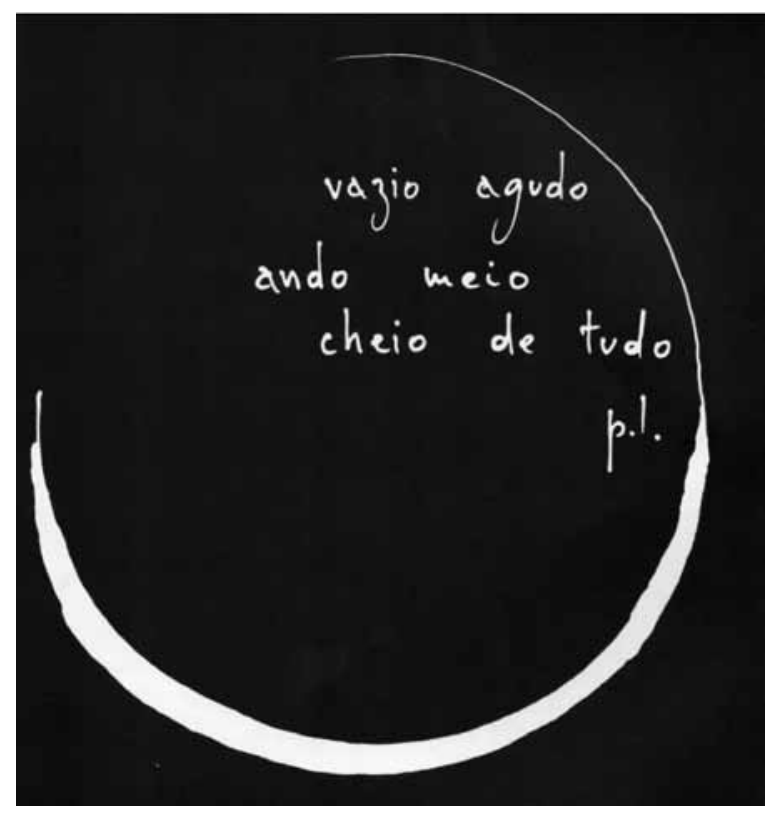

Si nos atenemos a la tradicional identificación entre el poeta y la naturaleza buscada en el haiku, nos daremos cuenta que aquí el sujeto (que incluso firma con sus iniciales) no se ha eliminado en pos de su objeto, ni tampoco se propone un paralelismo. Se trata, más bien, de una inversión: mientras la persona se llena, la luna se va vaciando, como en una transfusión de su esencia. Igualmente se relaciona con el radical sentido de impermanencia que domina el zen, que Leminski también había representado en otro poema mediante la imagen de una luna que se retira al mismo tiempo que su reflejo dibujado con letras va desapareciendo en el agua (con la misma fugacidad que la rana de Basho):

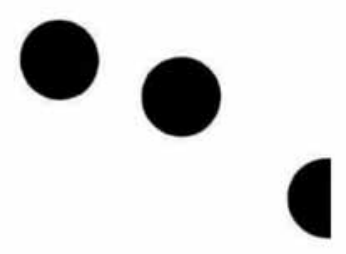

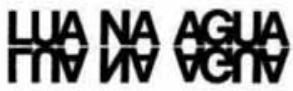 \\ ALCEMA WA \\ WA ALCUMA}

(Caprichos \& relaxos 134) 
Es preciso, sin embargo, dar un giro: hasta ahora, hemos seguido la traducción de "cheio" como "lleno", que sin duda concordaba con el aura plácida de la imagen del poema. Podríamos leerlo, sin embargo, en una acepción distinta, como "harto" o "colmado", según se ocupa en la expresión coloquial "ficar de saco cheio" (irritarse, fastidiarse o, como me propuso Brenda López, "estar hasta aquí"). Así lo entendió su traductor al inglés, Chris Daniels:

\author{
sharp void \\ i'm a little \\ fed up with everything \\ (Winterverno)
}

Si recurrimos al correlato biográfico, esta sería la lectura más pertinente: tras su separación y el agravamiento de su alcoholismo, de deudas, problemas laborales, los últimos meses de vida fueron particularmente autodestructivos para el autor. Casi un kamikase, cada vez se acercaba más a su otro modelo japonés, Mishima, cuyo harakiri representa tragicómicamente en un programa de TV Bandeirantes ${ }^{3}$. El vacío agudo podría entenderse como algún tipo de dolencia que le impide andar correctamente (anda "a medias"), y que lo tiene colapsado. En vez de una escena contemplativa mirando la luna, estas líneas podrían corresponder a las frases dichas por alguien que tras un día de trabajo llega a la barra de un bar y comenta que ya no aguanta más. Existe incluso un corto animado de Cristiane Fariah y Leonardo Arantes inspirado en este poema, que agranda aún más la situación, al mostrar un personaje abrumado, de cuyo interior surgen innumerables objetos que terminan por aplastarlo.

Pero hay más (o menos...). Josely Vianna Baptista señala que algunos de los poemas de Winterverno pasaron a ser incluidos en otro libro póstumo, La vie en close, y efectivamente este fue uno de ellos. Esta versión, sin embargo, consta solo del último verso:

$$
\begin{aligned}
& \text { cheio de tudo } \\
& \text { (La vie en close 123). }
\end{aligned}
$$

Ya no hay un sujeto, pues ha desaparecido la marca verbal de la primera persona, y la expresión puede entenderse de manera impersonal. Igualmente, la ausencia de los versos previos, que proponían un desarrollo escalonado, hace que esta afirmación rotunda se presente de manera sorpresiva. De ese modo, la antinomia entre los dos sentidos posibles de este verso (un proceso que culminaba en la plenitud vital versus otro que desembocaba en una crisis existencial) se desactiva, y nos enfrentamos a una experiencia que coincide perfectamente con la definición de satori que ofrece Suzuki: "Es una especie de catástrofe espiritual que se presenta súbitamente, si se ha acumulado un abundante material de conceptos y argumentaciones. Esta acumulación ha alcanzado el límite de carga admisible, el edificio todo se derrumba en sí y he aquí que un nuevo cielo se abre a lo lejos . . . . El Satori se apodera de un hombre cuando él siente que ha agotado todo su ser" (138).

\footnotetext{
3 Puede verse un precario registro en la segunda mitad de este video: http://www.youtube. com/watch?v=0pPBxqTjx4U\&feature=player_embedded $\# \mathrm{t}=119$
} 
Revisemos otro detalle gráfico: las palabras de este verso están ubicadas en el lugar correspondiente al tercer verso, no en el del primero, lo que hace más patente la ausencia de los dos versos iniciales. Es más, si revisamos el índice descubriremos que lleva justamente el título "vazio agudo". Considerando que Leminski se preocupaba bastante de los títulos (como se observa en su artículo "O nome do poema" en Anseios crípticos) y que habría preparado la edición de este volumen junto a su viuda, no creo que se trate un error, sino de la advertencia de que algo se ha eliminado. Una vez que se ha llegado al satori (este satori que disuelve las categorías binarias que determinan al sujeto), los medios utilizados para alcanzarlo se vuelven descartables. Las palabras solo han servido para ser quitadas y abrir un espacio. El poema, entonces, no es un manual de instrucciones, no ofrece lecciones, no explica nada: es la representación directa, sin mediaciones, del vacío.

Otros poetas han resuelto el mismo desafío recurriendo a las estrategias visuales. Podemos pensar en el conocido poema concreto "silencio" de Eugen Gomringer, pero Pedro Xisto, el otro poeta concreto que también influyó a Leminski, nos muestra igualmente un vacío que se hace más profundo cuando se han eliminado las letras:

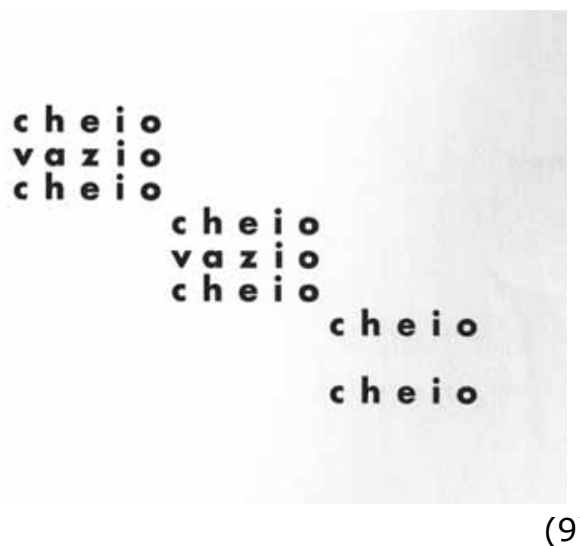

Un gesto similar podemos encontrar en el poeta japonés Shisui. En 1769, cuando estaba a punto de morir, sus seguidores le pidieron que escribiera un poema a la muerte. Sin recurrir a las palabras, dibujó este círculo:

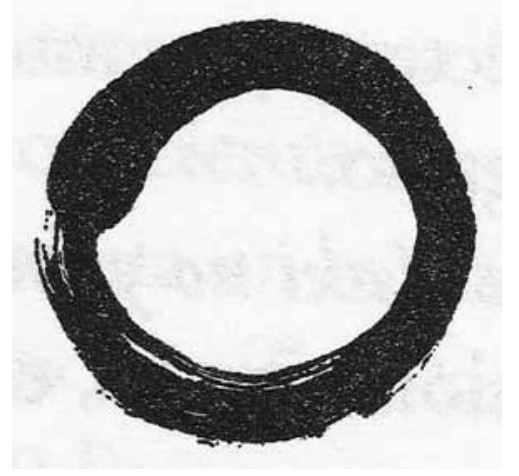


En su comentario a este poema, Yoel Hoffman explica que el círculo es un símbolo fundamental en el budismo y "[r]epresenta el vacío -la esencia de todo- y la iluminación, y quizá sugiera también el perfil de la luna llena, otro símbolo de la iluminación" (242).

No sé hasta qué punto Leminski haya buscado en su poesía realizar un gesto tan puro y rotundo como el de Shisui. Como señalé al inicio, eran demasiadas las influencias mezcladas en su cabeza. Su vivencia del budismo fue ecléctica, y quizás a más de alguno le parezca una impostura o una provocación. Por momentos tiendo a pensar que en su escritura predominó mucho más el afán de un bufón o de un malabarista. En el caso del poema que he venido analizando, podemos pensar perfectamente en un publicista que recorta su eslogan para que sea más fácilmente recordable, o un editor que elimina el pie de una foto, para no obstruir su mensaje. Pero, al final, sigo creyendo que ese sencillo gesto de borrar dos versos para hacer más espacio al vacío, como si quisiera invitarnos a borrar nosotros mismos la última línea, sigue siendo el gesto más profundamente zen de Leminski.

\section{Obras citadas}

"Antologia da Rã". Caqui. Revista Brasileira de Haicai. 24 abr. 2010. <http:// www.kakinet.com/caqui/furuike.shtml>

Barthes, Roland. El imperio de los signos. Trad. Adolfo García Ortega. Barcelona: Seix Barral, 2007.

Basho, Matsuo. Senda hacia tierras hondas. Trad. Antonio Cabezas. Madrid: Ediciones Hiperión, 1993.

Bouso, Raquel. El zen. Barcelona: Fragmenta Editorial, 2008.

Cabezas, Antonio (ed.). Jaikus inmortales. Madrid: Ediciones Hiperión, 1994.

Campos, Augusto de. Não. São Paulo: Editora Perspectiva, 2003.

Campos, Haroldo de. A arte no horizonte do provável e outros ensaios. São Paulo: Editora Perspectiva, 1977.

Crisantempo. São Paulo: Editora Perspectiva, 2004.

Dick, André y Fabiano Calixto (ed.). A linha que nunca termina. Pensando Paulo Leminski. Rio de Janeiro: Lamparina editora, 2004.

Fariah, Cristiane y Leonardo Arantes: "Vazio agudo". Video. 2008. 23 oct. 2010. <http://www.youtube.com/watch?v=7Cvvh1YF_m8>

Franchetti, Paulo. "Haicai, haicais". Entr. Wanderson Lima. Agulha, Revista de Cultura No 42, dezembro de 2004. 21 sep. 2009. <http://www. jornaldepoesia.jor.br/ag42franchetti.htm> "O Haicai no Brasil". Alea: Estudos Neolatinos, vol. 10, № 2, july/dec. 2008: 256-69.

Goga, H. Masuda. O haikai no Brasil. História e desenvolvimento. Trad. José Yamashiro. [São Paulo: Editora Oriento, 1988]. Caqui. Revista Brasileira de Haicai. 21 sep. 2009. <http://www.kakinet.com/caqui/brasil.htm>

Hoffman, Yoel (ed.). Poemas japoneses a la muerte. Escritos por monjes zen y poetas de haiku en el umbral de la muerte. Trad. Eduardo Moga. Barcelona: DVD Ediciones, 2001.

Jiménez, Reynaldo (ed.). Haiku. Buenos Aires: Editorial Leviatán, 1997.

Leminski, Paulo. Catatau. [1975]. [Curitiba: Ed. Travessa dos Editores, 2004]. Versión digitalizada por Digital Source. Archivo PDF. 
Caprichos \& relaxos. [1983]. [São Paulo: Editora Brasiliense, 1985]Versión digitalizada por Digital Source. Archivo PDF.

Anseios crípticos. [Curitiba: Criar Edições, 1986]. Versión digitalizada por Editora Barba Ruiva. Archivo PDF.

Distraídos venceremos. [1987]. São Paulo: Editora Brasiliense, 1995.

- Vida. Cruz e Sousa, Bashô, Jesus e Trótski. Porto Alegre: Editora Sulina, 1990.

. La vie en close. [1991]. São Paulo: Editora Brasiliense, 1994.

. Ensaios e Anseios Crípticos. Ed. Alice Ruiz y Aurea Leminski. Curitiba: Pólo Editorial do Paraná, 1997.

. Anseios crípticos 2. [Curitiba: Criar Edições, 2001]. Versión digitalizada por Digital Source. Archivo PDF.

Leminskiana. Antología variada. Ed. Mario Cámara. Buenos Aires: Ediciones Corregidor, 2005.

y Régis Bonvicino. Envie meu diccionário. Cartas e Alguma Crítica. São Paulo: Editora 34, 1999.

y João Suplicy. Winterverno. [1994]. Trad. Chris Daniels. São Paulo: Iluminuras, 2001.

Marques, Fabrício. Aço em flor. A poesia de Paulo Leminski. Belo Horizonte: Autêntica, 2001.

McCaffery, Steve. The Basho Variations. Toronto: BookThug, 2007.

Paz, Octavio. Obra poética II (1969-1988). Obras Completas, tomo 12. Barcelona/México D.F.: Círculo de Lectores/Fondo de Cultura Económica, 2003/2004.

Plaza, Julio. Tradução intersemiótica. São Paulo: Perspectiva, 2003.

Silva, Alberto (ed.). El libro del haiku. Buenos Aires: Bajo la luna, 2005.

Suzuki, D. T. Introducción al budismo zen. Bilbao: Ediciones Mensajero, 2006.

Ungaretti, Giuseppe. La alegría. Trad. Carlos Vitale. Tarragona: Ediciones Igitur, 1997.

Vaz, Toninho. Paulo Leminski. O bandido que sabia latim [Rio de Janeiro: Record, 2001]. Versión digitalizada por Digital Source. Archivo PDF.

Watts, Alan W. The Way of Zen. New York: Mentor Books, 1959.

Xisto, Pedro. As águas glaucas. São Paulo: Berlendis \& Vertecchia, 2006. 